\title{
Analysis of a full-scale slope failure test on a sludge embankment
}

Kristof Verreydt MSC

Project Engineer, Triconsult nv, Lummen, Belgium; Doctoral student, Department of Civil Engineering, KU Leuven, Leuven, Belgium (corresponding author: kristof.verreydt@student.kuleuven.be) (Orcid:0000-0002-6331-8855)

Dionys Van Gemert MSEng, PhD

Emeritus Professor, Department of Civil Engineering, KU Leuven, Leuven, Belgium (Orcid:0000-0002-2023-7019)

Pieter Rauwoens MSEng, PhD

Assistant Professor, Department of Civil Engineering, KU Leuven, Leuven, Belgium (Orcid:0000-0002-8226-6536)
Jules Houtmeyers MSEng, PhD

Honorary Director Environment, Tessenderlo Group, Ham, Belgium Tom Claes MSEng

Group Environmental Manager, Tessenderlo Group, Ham, Belgium (Orcid:0000-0002-7581-3327)

In the framework of the reorganisation of several historical wet deposits of a chemical processing plant, one of the oldest wet deposits was cleared because of environmental and economic considerations. The stored sludge (around $350000 \mathrm{~m}^{3}$ ) was transported to the neighbouring environmentally controlled deposit, Veldhoven (Ham, Belgium), and stacked on top of existing sludge, using the sludge itself as dyke construction material. To calibrate the embankment stability analysis procedure, a full-scale slope failure test was conducted on an embankment built with industrial calcium fluoride $\left(\mathrm{CaF}_{2}\right)$ sludge. The Norwegian Geotechnical Institute-active, direct simple shear, passive (NGI-ADP) material model was used to perform a finite-element back-analysis of the full-scale slope failure test. Anisotropic conversion factors are suggested to convert the in situ measured vane shear strengths to shear strengths at different anisotropic stress states, which can then be implemented in the NGI-ADP model. The simple and quickly executable in situ vane shear test was used to master the uncertainties linked to the heterogeneity of the sludge. Sludge heterogeneity not only depends on sludge composition, but also on manipulations during transport and handling of the sludge at the construction of the elevations. The results of the full-scale slope failure test support the proposed modelling of the embankment stability problem.

\section{Notation}

$b \quad$ time factor

$C_{\mathrm{c}} \quad$ compressibility index

$C_{\alpha} \quad$ creep coefficient

$c^{\prime} \quad$ cohesion

$c_{\mathrm{v}} \quad$ coefficient of consolidation

$D \quad$ depth

E Young's modulus

$E_{\text {oed }} \quad$ oedometer modulus

e void ratio

$G_{\text {ur }} \quad$ unloading/reloading shear modulus

$k \quad$ coefficient of permeability

$L \quad$ length

$m$ power

$P_{\text {ref }} \quad$ reference pressure

$S \quad$ undrained shear strength ratio $\left(=s_{\mathrm{u}} / \sigma^{\prime}\right)$

$S_{\mathrm{FV}} \quad$ undrained shear strength ratio from field vane test

$S_{\mathrm{TC}} \quad$ undrained shear strength ratio from triaxial compression test

$S_{\alpha} \quad$ undrained shear strength ratio for anisotropic stress state

$s_{\mathrm{u}} \quad$ undrained shear strength

$s_{\mathrm{u}, \mathrm{DSS}} \quad$ undrained shear strength from direct simple shear test

$s_{\mathrm{u}, \mathrm{FV}} \quad$ undrained shear strength from field vane test

$s_{\mathrm{u}, t_{0}} \quad$ undrained shear strength at time $t_{0}$

$s_{\mathrm{u}, \mathrm{TC}} \quad$ undrained shear strength from triaxial compression test

$s_{\mathrm{u}, \mathrm{TE}} \quad$ undrained shear strength from triaxial extension test

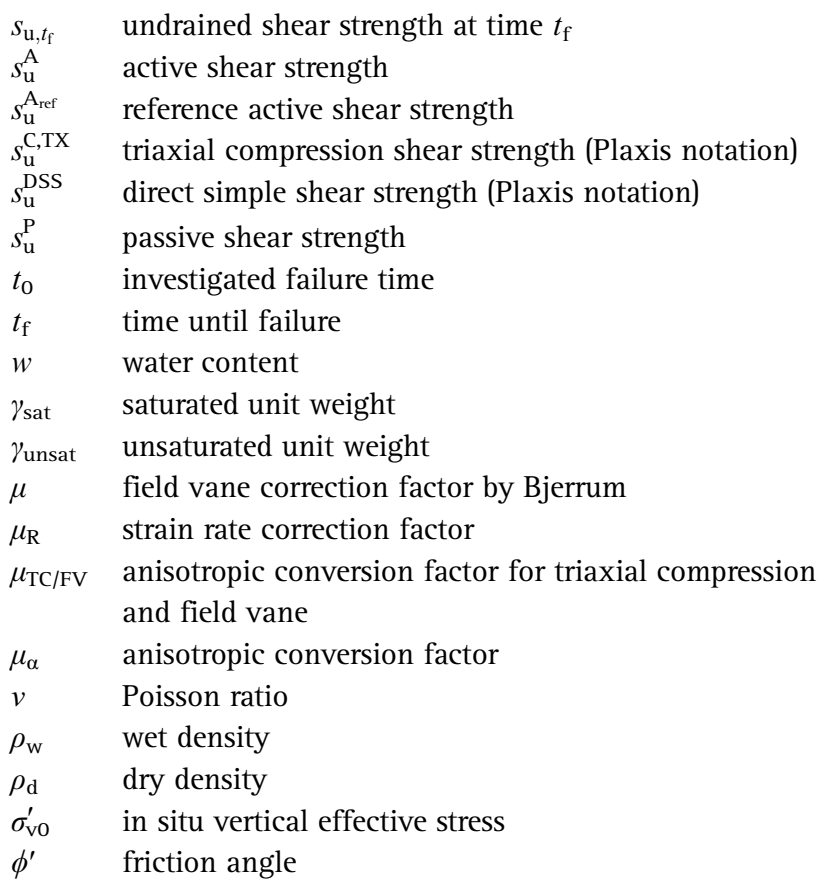

\section{Introduction}

Knowledge of the shear resistance is essential in slope stability calculations. Performing laboratory and/or in situ testing is 
crucial for the determination of the shear strength properties. When relying solely on laboratory tests, the dataset will commonly be limited due to the time-consuming and relatively costly tests. Hence, high-quality data on the examined points will be available, but the variation of the investigated properties is unknown. On the other hand, when performing a large series of in situ tests (i.e. vane shear test, cone penetration test and so on) data are gathered on various locations and depths. This provides information on the variation of the properties across the investigated area. The positive and negative aspects of laboratory and in situ testing are to be considered when analysing a certain material or construction.

This paper deals with the (physical) characterisation of (historical) industrial sludge, arising from the production of phosphate fertiliser and feed phosphate at a chemical processing plant in Ham (Belgium), as studied in earlier research by Yonatan et al. (2008) and Verreydt et al. (2014). The sludge mainly consists of calcium fluoride-silicon dioxide $\left(\mathrm{CaF}_{2}-\mathrm{SiO}_{2}\right)$ compounds. The storage capacity of a wet industrial sludge deposit at the processing plant is being increased by elevating the deposit with an embankment built solely with naturally as well as mechanically consolidated sludge. The consolidated sludge shows similarities to clay, given its low permeability $\left( \pm 1 \times 10^{-9} \mathrm{~m} / \mathrm{s}\right)$ and high water content ( 35 to $120 \%$ ).

The slope failure test is a part of an extensive testing programme concerning the reorganisation of several sludge deposits. The characterisation of geotechnical behaviour as well as the numerical simulation of settlement behaviour of freshly dumped sludge, filter pressed sludge and naturally dried sludge are the main aspects of the research programme. This included, among others, a study of the settlement of a full-scale embankment $(200 \times 70 \times 8 \mathrm{~m})$ built with filter-pressed sludge (Tennekoon, 2007). Filter-pressed sludge has been dewatered by compressing the sludge at a pressure of 15 bars $(1500 \mathrm{kPa})$. The process of filter pressing results in a reduction of the water content from over $300 \%$ (watery sludge) to around $80 \%$ (solid sludge 'cakes'). The sludge is consolidated at a pressure of around $1500 \mathrm{kPa}$, and subsequently the filter 'cakes' have an undrained vane shear strength of from 60 up to $120 \mathrm{kPa}$ after being dumped, compacted and spread on site.

In the present study the embankment is not built any longer with filter-pressed sludge; instead naturally consolidated sludge is used. The sludge originates from sludge production decades ago. Watery sludge, with a dry matter content of around 5\%, was pumped into the settling basins. Larger particles settled closer to the inlet point whereas the fine particles settled much further into the basin, with variation in density and granular distribution as a result. The inlet point was moved several times to obtain a more uniform filling of the reservoir. A layered structure of the densified sludge was the result of the method used (Figure 1). The sludge has been consolidating in the deposit site for several decades. The naturally dried (partially) consolidated sludge has a

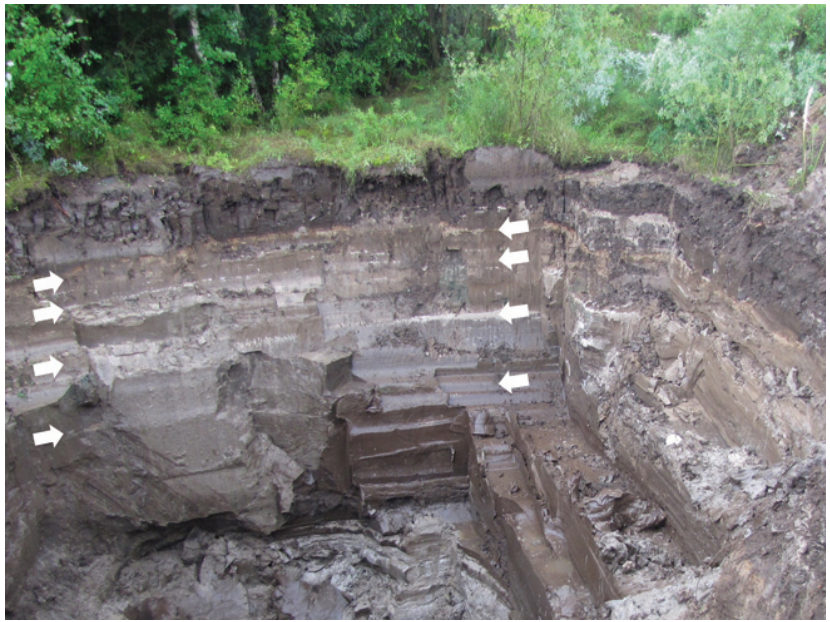

Figure 1. Different layers visible in the consolidated sludge at a test pit

water content ranging from 50 up to $120 \%$. Currently some of the deposit sites are being reorganised in the context of the redevelopment of an industrial area. One of the oldest depot sites, containing $350000 \mathrm{~m}^{3}$ of sludge, is being decommissioned. The sludge is excavated, transported and stacked at the Veldhoven deposit site. The decommissioned deposit had a thickness of around $7 \mathrm{~m}$. The deposit was not cleared layer by layer (horizontally) but but using a near to vertical excavation slope. Consequently, the top, intermediate and bottom sludge layers are mixed, resulting in a combination of highly and only lightly consolidated sludge. Furthermore, a part of the sandy subsoil is excavated as well, mixing in a varying quantity of sand. Such sludge could only be filter pressed after remixing with water to enable it to be pumped into the filter presses. Rewetting already dried sludge would be energetically and economically irresponsible. On the receiving deposit site the sludge is dumped, spread with dozers and allowed to dry (depending on the weather conditions) before a new layer is added. Because of the numerous manipulations and the historical background of the sludge consolidation, the shear strength shows a significant spread.

The objective of the full-scale slope failure test presented (Figure 2) is to calibrate the embankment stability analysis procedure. The use of the vane shear test, for a reliable estimation of the undrained shear strength of the sludge deposits and to assess the scatter, is evaluated. The construction and instrumentation of the test embankment are presented below, as well as the characterisation of the industrial sludge present in the test embankment. Finally, the results of the load test of the embankment are discussed and a back-calculation is performed on the results of the slope failure test.

\section{Geometry and construction of test embankment}

To simulate the raising procedure of the terrain and the influence of self-consolidation, a full-scale test embankment was 
Geotechnical Engineering

Volume 172 Issue GE5
Analysis of a full-scale slope failure test on a sludge embankment

Verreydt, Van Gemert, Rauwoens, Houtmeyers and Claes

\section{Offprint provided courtesy of www.icevirtuallibrary.com}

Author copy for personal use, not for distribution

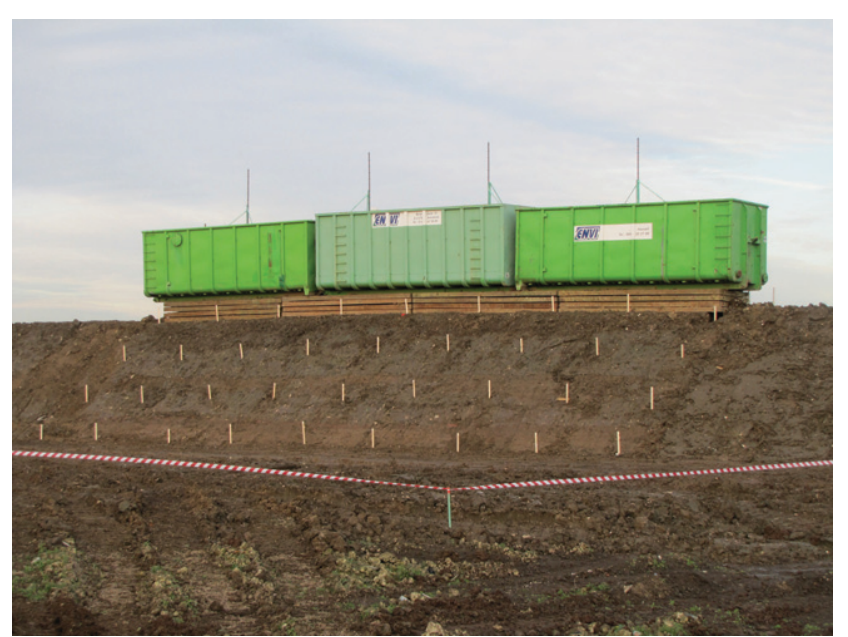

Figure 2. Test set-up of full-scale slope failure test

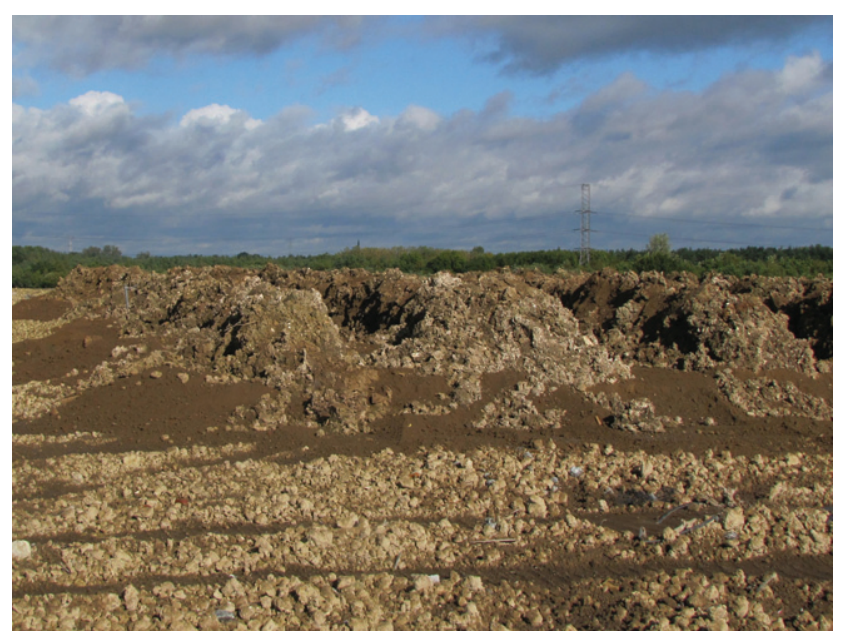

Figure 3. Dumping of the sludge in ridges during the construction of test embankment to enhance drying by wind and sun built. The construction of the test embankment was similar to the way the level of the entire deposit site will be raised. The sludge material is transported onto the site using dumping trucks. The wet, solid sludge is first dumped in ridges (Figure 3). By doing so, the evaporation surface is increased to enhance drying by wind and sun, to reduce the water content of the sludge. The sludge is left to rest for several days (depending on the weather conditions), after which the piles are levelled with a bulldozer. A sludge layer with a thickness of around 1.0 to $1.5 \mathrm{~m}$ is generally created. The test embankment consisted of two layers with a total thickness of around $3 \mathrm{~m}$ on top of a sand layer.

The experiment was planned in two stages: a first test was conducted shortly after construction of the embankment; a second test was planned 1 year after construction. With these tests, the aim was to determine the actual shear resistance of unconsolidated (stage 1) and (partially) consolidated sludge (stage 2) at slope failure.

The test embankment, shown in Figure 2, measures $15 \mathrm{~m}$ by $60 \mathrm{~m}$ with a height of around $4 \mathrm{~m}$. The bottom layer consists of a $1 \mathrm{~m}$ thick sand layer. On top of this layer, $3 \mathrm{~m}$ of sludge was piled up. The slope inclination of the test embankment is $38 \cdot 6^{\circ}$. The construction of the embankment took place within a period of about 2 months (September-October 2015). The location of the test zone on the sludge deposit, Veldhoven, located at Ham, Belgium, is shown in Figure 4. Figure 5 shows the cross-section of the test embankment.

To initiate slope failure, the embankment is loaded with three $40 \mathrm{~m}^{3}$ containers, placed on top of a stack of crane mats, positioned near the edge of the slope. The crane mats, weighing around $1 \mathrm{t}$ each, are placed in two rows and stacked four elements high. The containers are gradually filled with water, until slope failure occurs. To calculate the ultimate load, the degree of filling in the containers is monitored during the test by using floats. The floats were attached to measuring poles protruding above the containers to allow measurement of the

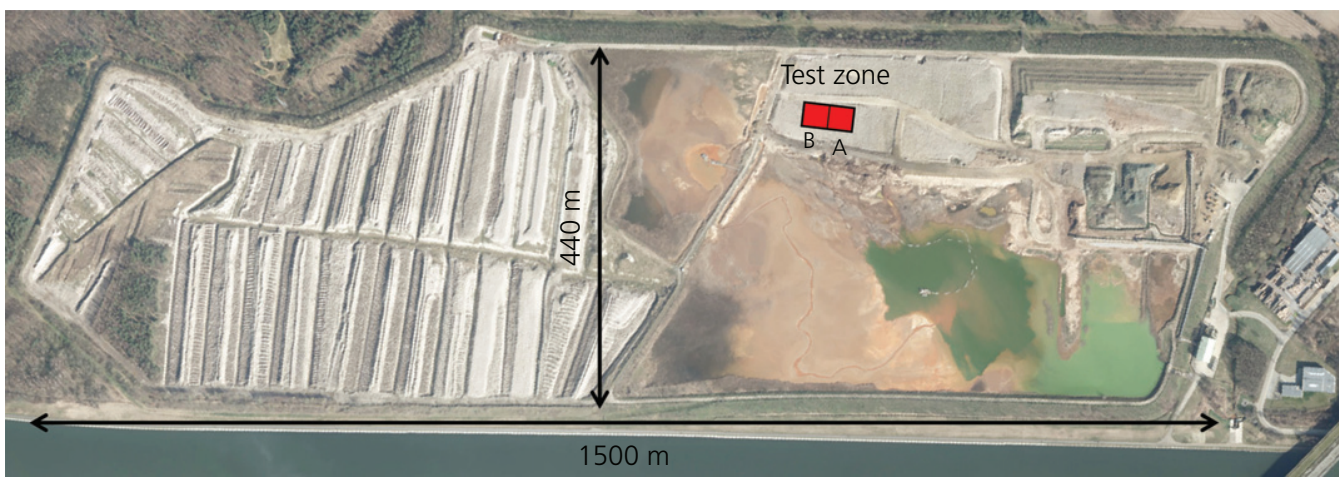

Figure 4. Aerial view on sludge deposit Veldhoven (Ham, Belgium) in 2014 (GeoVlaanderen), showing the location of the test zone 


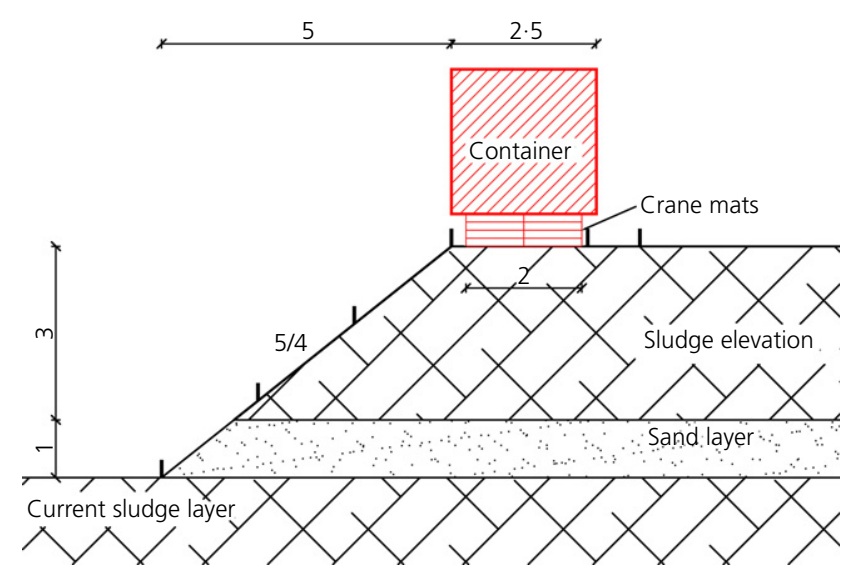

Figure 5. Cross-section of test set-up of full-scale slope failure test

degree of filling from a safe distance. The deformations of the embankment are monitored by means of reference points on wooden posts, placed behind the containers and on the slope. The positions of these posts are recorded with a theodolite before the start of the test and after each loading step.

The following steps were maintained during the slope failure test

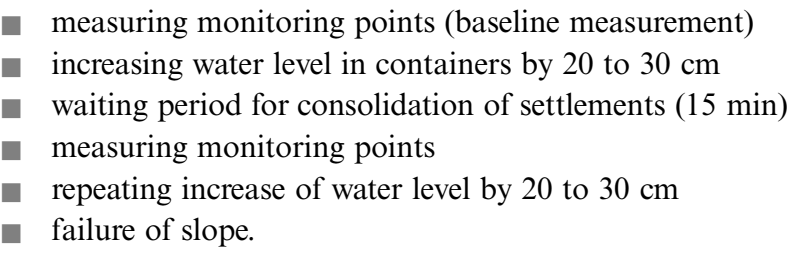

\section{Geotechnical analysis of sludge}

Various tests on the industrial calcium fluoride $\left(\mathrm{CaF}_{2}\right)$ sludge have been carried out on sludge samples in earlier research (Tennekoon, 2007; Yonatan et al., 2008, 2009a, 2009b). The chemical composition of the industrial sludge consists mainly of calcium difluoride $\left(\mathrm{CaF}_{2}\right)(50-60 \%)$, bound to silicon dioxide $\left(\mathrm{SiO}_{2}\right)(12-14 \%)$. Furthermore, sulfates (iron (II) sulfate $\left(\mathrm{FeSO}_{4}\right)$ and aluminium sulfate $\left.\left(\mathrm{Al}_{2}\left(\mathrm{SO}_{4}\right)_{3}\right), 7-8 \%\right)$, phosphorus pentoxide $\left(\mathrm{P}_{2} \mathrm{O}_{5}\right)$ (4-8\%) and organic content $(2-3 \%)$ are present, combined with a small fraction of heavy metals $(0 \cdot 05-0 \cdot 15 \%)$. The geotechnical characteristics were determined by field and laboratory tests. An overview of the characteristics is presented in Table 1. The current investigation focuses on the short-term, undrained behaviour of the sludge, which is relevant for stability checks during the construction phase of embankments on and using the industrial sludge.

As part of the reorganisation of the company's sludge deposits, one deposit has been excavated and the sludge is piled up at the Veldhoven deposit site. The excavated sludge had been
Table 1. Mechanical properties of industrial calcium fluoride sludge

\begin{tabular}{|c|c|c|c|}
\hline Property & Symbol & Unit & $\begin{array}{l}\text { Calcium } \\
\text { fluoride sludge }\end{array}$ \\
\hline Wet density & $\rho_{\mathrm{w}}$ & $\mathrm{kN} / \mathrm{m}^{3}$ & $14 \cdot 0-17 \cdot 0$ \\
\hline Dry density & $\rho_{\mathrm{d}}$ & $\mathrm{kN} / \mathrm{m}^{3}$ & $6 \cdot 5-11 \cdot 5$ \\
\hline Water content & $w$ & $\%$ & $35-120$ \\
\hline Void ratio & e & - & $1 \cdot 4-3 \cdot 3$ \\
\hline $\mathrm{PI}$ & - & - & $30-60$ \\
\hline Oedometer modulus & $E_{\text {oed }}{ }^{\text {ref }}$ & $\mathrm{kPa}$ & $1100-3100$ \\
\hline Reference pressure & $P_{\text {ref }}$ & $\mathrm{kPa}$ & 100 \\
\hline Power & $m$ & - & $0 \cdot 5-1$ \\
\hline Compressibility index & $C_{c}$ & - & $0.13-0.64$ \\
\hline Creep coefficient & $C_{\alpha}$ & - & $0.005-0.02$ \\
\hline $\begin{array}{l}\text { Coefficient of } \\
\text { permeability }\end{array}$ & $k_{\text {ref }}$ & $\mathrm{m} / \mathrm{s}$ & $0.2 \times 10^{-9}-3.0 \times 10^{-9}$ \\
\hline $\begin{array}{l}\text { Coefficient of } \\
\text { consolidation }\end{array}$ & $c_{v}$ & $\mathrm{~m}^{2} /$ year & $1 \cdot 4-14 \cdot 0$ \\
\hline Friction angle & $\phi^{\prime}$ & degrees & $28-32$ \\
\hline Cohesion & $c^{\prime}$ & $\mathrm{kPa}$ & $5-15$ \\
\hline
\end{tabular}

naturally consolidating and drying for years to decades at the original site. Because of the natural drying of the sludge, additional compaction (due to shrinkage) had occurred. As a result, the sludge behaves as an overconsolidated soil. The effect of natural drying has the greatest influence on the superficial layers, whereas deeper layers are not influenced and are normally consolidated or even unconsolidated. The total thickness of the decommissioned sludge deposit was around $7 \mathrm{~m}$. The manipulations of the sludge (excavation, transport, dumping, levelling, etc.) mixes the overconsolidated and the (un)consolidated sludge, altering the mechanical properties and causing large spreads on these properties. Performing a limited number of laboratory tests (triaxial test, direct shear test and so on) for the determination of the shear resistance may provide very accurate data on the properties in discrete points, but is unlikely to give a relevant representation of the spread of the results over the entire embankment or the entire deposit. Therefore, it was decided to carry out an extended series of easily executable vane shear tests, distributed over the deposit surface, allowing the variation of the shear strength to be mapped.

The undrained shear strength of the freshly dumped and wheel compacted sludge was estimated with vane shear tests, in accordance with ASTM D2573 (ASTM, 2018). The vane tests were carried out at six locations on top of the test embankment, each time at three depths $(-0.5 \mathrm{~m},-1.5 \mathrm{~m},-2.5 \mathrm{~m})$ and at two sections of the slope (Figure 6). At each location, samples were taken to determine the plasticity index (PI). The results of vane shear tests, carried out on the test embankment a few weeks after its construction, are shown in Figure 7. Along the periphery of the entire deposit site, various tests (laboratory and in situ) are carried out every $50 \mathrm{~m}$. Relative to the maximum height of the embankment of $9 \mathrm{~m}$, the ratio of testing spacing over height is $(50 / 9=) 5 \cdot 6$. The test 


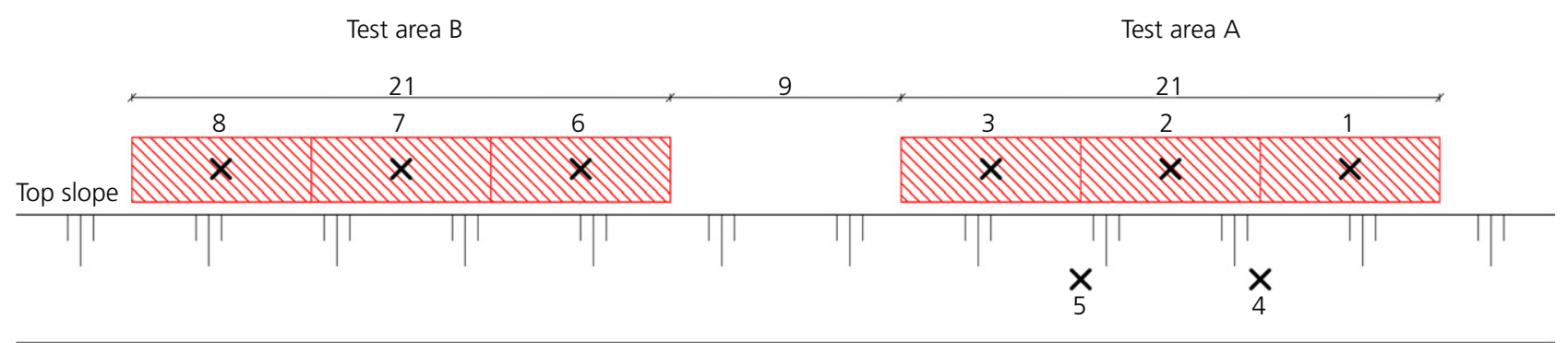

Bottom slope

Figure 6. Location of vane shear tests at test areas A and B

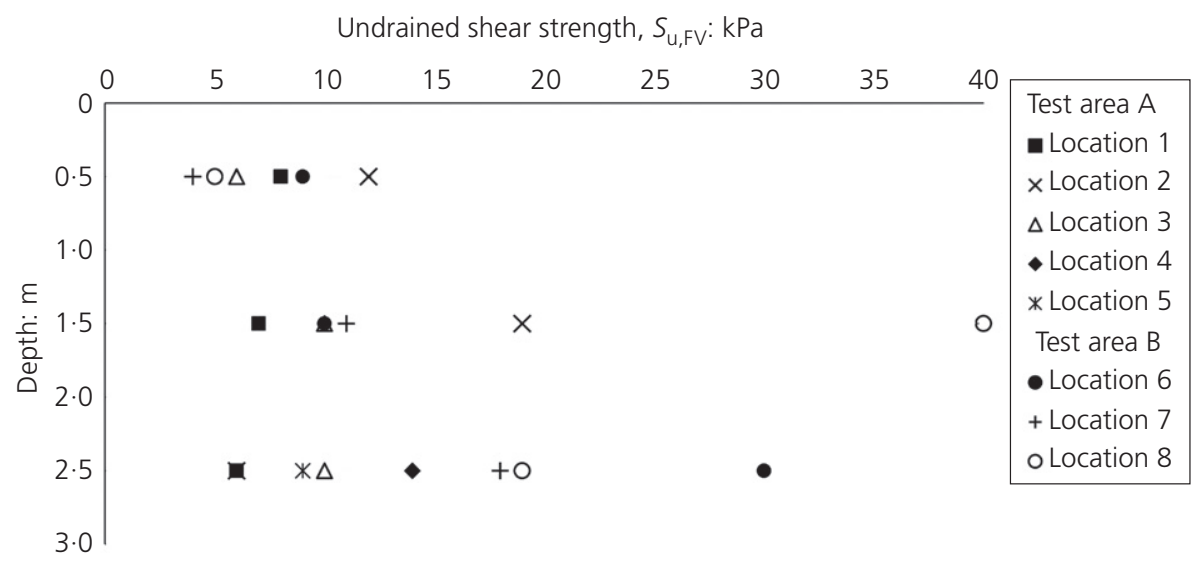

Figure 7. Undrained shear strength from vane shear test at test area A and B, at different depths

embankment is $3 \mathrm{~m}$ high (sludge layer) and vane tests were performed about every $7 \mathrm{~m}$, which results in a ratio of $2 \cdot 3$. The testing density on the test embankment is therefore more than twice as dense as on the actual deposit site.

The failure test of the embankment was intended to be split up into two phases, with the first phase being carried out on the first $30 \mathrm{~m}$ of the test embankment (zone A), shortly after completion of the embankment construction. The second phase was planned on the second half of the embankment (zone B), about 1 year after construction.

In zone $\mathrm{A}$, the average undrained shear resistance of the sludge is $9.7 \mathrm{kPa}$, with a standard deviation (SD) of $4.0 \mathrm{kPa}$ and a coefficient of variation (COV) of 0.41 . In zone $\mathrm{B}$ the mean value is $16 \cdot 2 \mathrm{kPa}$, with a SD of $12.0 \mathrm{kPa}$ and a COV of 0.74 . The results of the vane shear test indicate a (very) large spread, especially in zone $\mathrm{B}$. If the extreme values ( $\geq 30 \mathrm{kPa}$ ) measured in zone $\mathrm{B}$ are excluded, the average value is $10.9 \mathrm{kPa}$, with a $\mathrm{SD}$ of $5.8 \mathrm{kPa}$ $(\mathrm{COV}=0 \cdot 54)$. No correlation is observed between the shear strength and the depth. The exceptionally high resistance measured at a few locations may be due to local areas with denser compacted sludge or could be the result of local sand or stone inclusions. The large variations in the vane test results can be attributed to the manner of constructing the test embankment, as well as the origin of the sludge, as described above. Hence, the lower accuracy of the vane shear test, compared to lab tests (triaxial tests and so on), is compensated by the larger numbers of data points acquired on the test site, allowing the variation to be mapped. Nevertheless, calibration tests are advised to quantify the uncertainty of the vane shear tests compared to laboratory tests.

At the test embankment, calibration tests were executed on two soil samples which were subjected to an unconsolidated, undrained, triaxial compression test for determination of the undrained shear strength. At the extraction point of the samples, several vane shear tests were executed for comparison of both test methods. The laboratory test on the samples and the vane test were done several weeks after the slope failure test.

The undrained shear strengths in the unconsolidated, undrained, triaxial tests were $22 \cdot 0$ and $24.0 \mathrm{kPa}$ for samples 1 and 2, respectively. Five vane shear tests near sample point 1 indicated an undrained shear strength ranging from 23.7 up to $41.0 \mathrm{kPa}$, with an average of $30.1 \mathrm{kPa}$ and a SD of 6.8 . At sample point 2 , the undrained shear strength from five vane tests ranged from 18.5 up to $30.0 \mathrm{kPa}$, with an average of 
$24 \cdot 1 \mathrm{kPa}$ and a SD of $5 \cdot 5$. Even with tests in close proximity to each other (only several tens of centimetres apart) the undrained shear strength, measured with the vane shear test, varies significantly. Based on the results of the calibration measurements, no clear correlation between the test methods could be observed. Therefore, it was decided not to carry out additional laboratory tests as they were unlikely to provide more relevant information.

According to ASTM D2573 (ASTM, 2018) a correction factor $\mu$ is to be used for correcting the raw results of the undrained shear strength determined with the vane apparatus. The correction factor developed by Bjerrum (1973), based on the PI, is used in the analysis. The average PI (ASTM, 2017) of the sludge material of the test embankment is $33.9 \%( \pm 3.0 \%)$, which results in a correction factor $(\mu)$ of 0.875 .

\section{Results of the full-scale slope failure test}

During the slope failure test, the deformations of the embankment were monitored as described in section 2. The results of the horizontal displacement are shown in Figure 8. A detailed visualisation of the horizontal deformations of the refence point of row $\mathrm{C}$ is presented in Figure 9. The displacement of the slope was measured with reflectors applied at the top of pickets, which protrude half a metre above the ground (slope) level. During the test, the pickets started tilting, due to the deformation of the soil. The influence of the tilt of the pickets was underestimated. To avoid erroneous measurements, the reflectors should have been placed as low as possible to the soil surface. The measured displacements are affected by the tilting and consequently do not represent the actual soil displacements, but merely give an impression of the deformation.

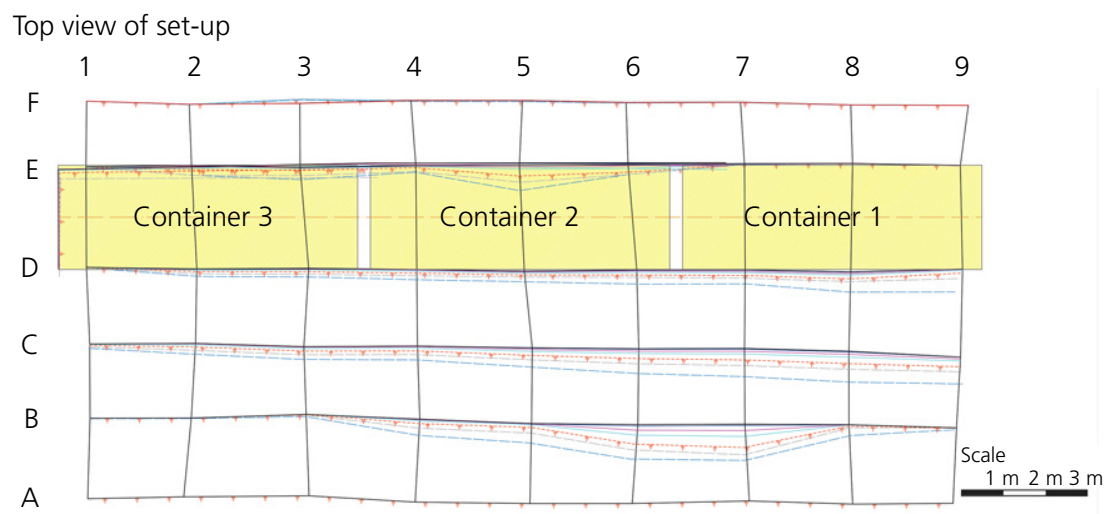

Figure 8. Grid of measuring points with horizontal deformations during slope failure test

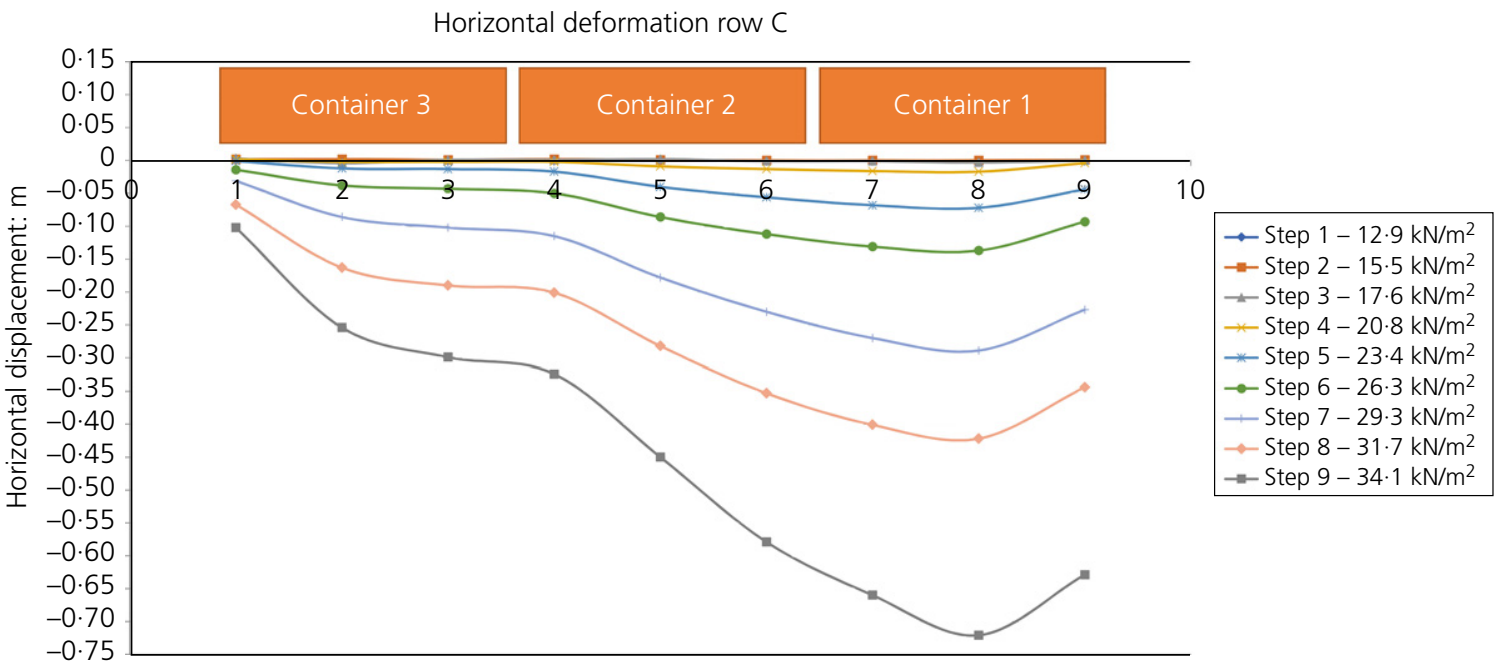

Figure 9. Horizontal movements of measuring points at row C. A full-colour version of this figure can be found on the ICE Virtual Library (www.icevirtuallibrary.com) 
Virtually no deformations were recorded during the first loading steps. Starting from an overload of approximately $23 \cdot 4 \mathrm{kN} / \mathrm{m}^{2}$ (step 5), the deformations increased systematically

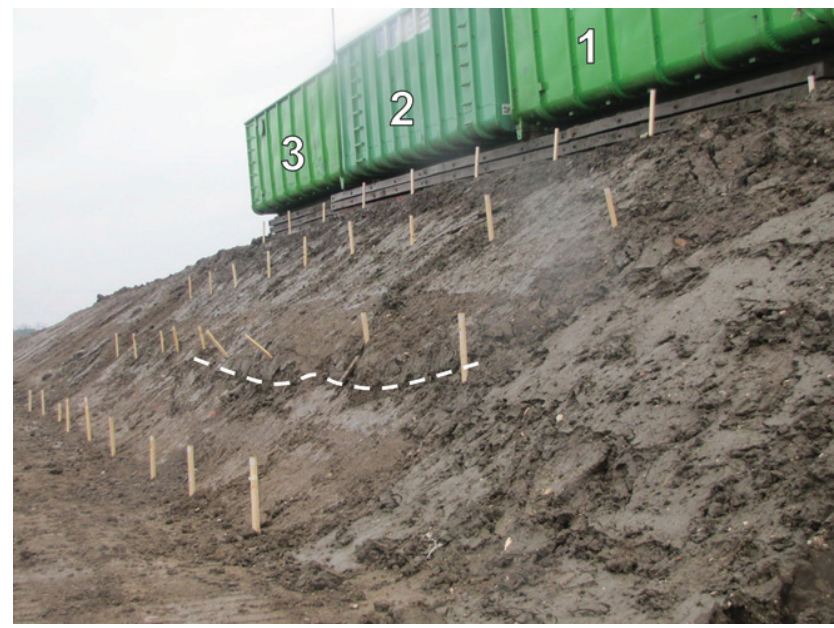

Figure 10. Bulge formed below container 1, just above the interface between the sand layer and the sludge with the applied load. Gradually a bulge formed below container 1, as shown in Figure 10.

At the further increase of the surcharge in step 9 (from 31.7 to $34 \cdot 1 \mathrm{kN} / \mathrm{m}^{2}$ ), large deformations were noticed, mainly at the zone under container 1 . The deformations resulted in a tilting of the container, causing the water to overflow. Increasing the surcharge became impossible. Furthermore, the deformations continued to increase under a constant load. A stable measurement of the reference points was no longer possible. Container 1 had to be retained with an excavator to prevent it from tipping over. The end of loading step 9 could not be reached. The failure load was estimated at $33 \mathrm{kN} / \mathrm{m}^{2}$, based on the water levels in the containers. The deformations at containers 2 and 3 were significantly smaller, but due to the large deformations at container 1 the test had to be terminated for safety reasons, and to avoid collapse and damage to the containers. The displacements measured on the reference points on the containers are given in Figures 11 and 12. Owing to the large displacements of container 1, some reference points were no longer within reach of the theodolite at a certain load.

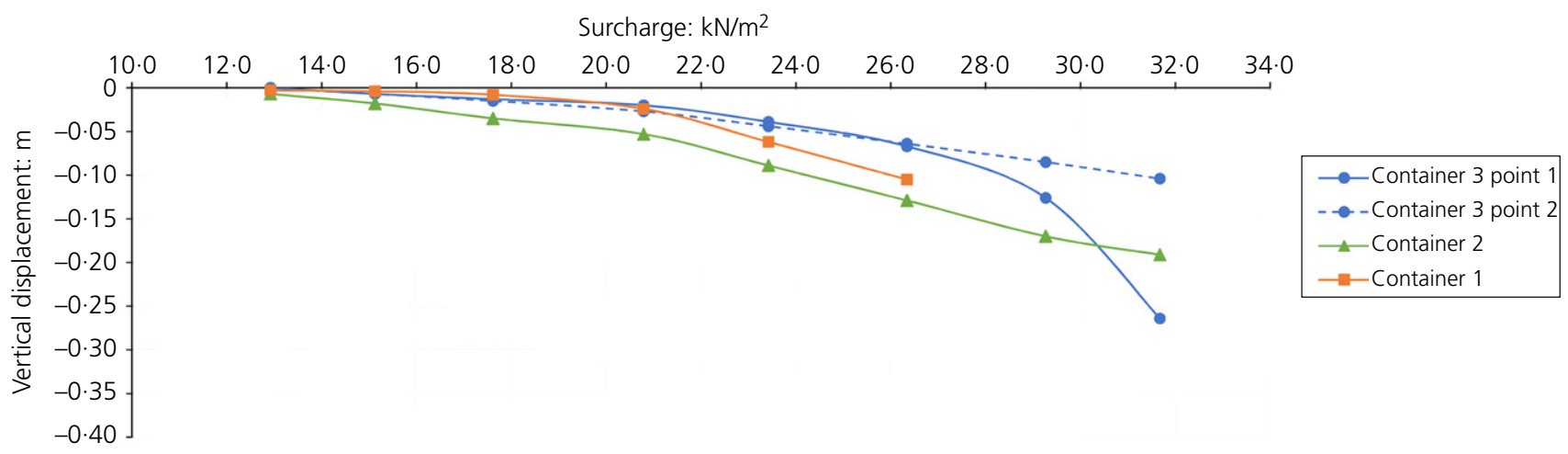

Figure 11. Vertical displacements of containers, monitored with two reference points on container 3 and one point on each of containers 1 and 2. After the surcharge of $26 \mathrm{kN} / \mathrm{m}^{2}$ container 2 overshadowed the reference point on container 1 
During the test large cracks appeared in the top surface of the embankment just behind the containers. The bulge, which formed in the slope just above the sand layer, initiated below container 1 but progressively spread along the entire length of the test area (Figure 10).

The slope failure test indicates that the sludge embankment can exhibit large deformations before failure occurs. Furthermore, the results of the monitoring of the deformation indicate significant differential displacements. Although absolute values of deformations are influenced by the inclination of the measuring poles, it is still obvious that the deformations at container 1 are more than double those at containers 2 and 3 . Those differences may be caused by variations in the mechanical properties of the sludge, most probably in turn caused by different stacking and compaction actions at the end of the test embankment.

\section{Back-calculation of slope failure test}

\subsection{Three-dimensional (3D) effects}

To estimate the ultimate surcharge on the embankment and the resulting average shear resistance of the sludge at failure, a two-dimensional (2D) finite-element model (Plaxis) was used. The test set-up consisted of three containers placed on the edge of the embankment. Only in the central area plane strain applies, as presumed in the 2D finite-element model. At the boundaries of the test set-up, edge effects will occur. Azzouz et al. (1983) investigated the increase of the factor of safety (FS) with actual 3D failure modes and compared them with $2 \mathrm{D}$ calculations. As a rule of thumb, the following equation might be applied to estimate the deviation of the FS of a full plane strain situation compared to the actual 3D set-up

1. $\frac{\mathrm{FS}_{3 \mathrm{D}}}{\mathrm{FS}_{2 \mathrm{D}}}=1+0 \cdot 7 \frac{\mathrm{D}}{L}$

In the equation above, $D$ and $L$ are, respectively, the depth of the shear surface and the length of the failure zone. For the test set-up in the current paper, the depth of the shear surface was assumed to be around $2 \mathrm{~m}$ and the length of the test area was $20.5 \mathrm{~m}$, resulting in a correction factor of 1.07 $\left(\mathrm{FS}_{3 \mathrm{D}} / \mathrm{FS}_{2 \mathrm{D}}\right)$. The maximum surcharge in the $2 \mathrm{D}$ analysis is recalculated with the correction factor for the FS. The accuracy of the calculated correction factor is limited given the estimated position of the shear plane. Its purpose is merely to give an idea of the order of magnitude of the deviation.

\subsection{Anisotropic behaviour}

The undrained shear strength depends on the orientation of the failure surface. This is due to the angle of the principal stress direction, which changes along the critical failure plane (Figure 13). The active, horizontal and passive part of a circular failure surface corresponds, respectively, to triaxial compression, direct simple shear and triaxial extension tests. In the investigated slope, slope failure is triggered by applying an overload on the embankment crest near the edge of the slope. By doing so, the failure mode of the sludge in the embankment is predominantly compression. At the bottom of the sludge layer (just above the sand layer), the failure mode can be between triaxial compression or direct simple shear. A failure mode of triaxial extension is very unlikely to occur in this set-up.
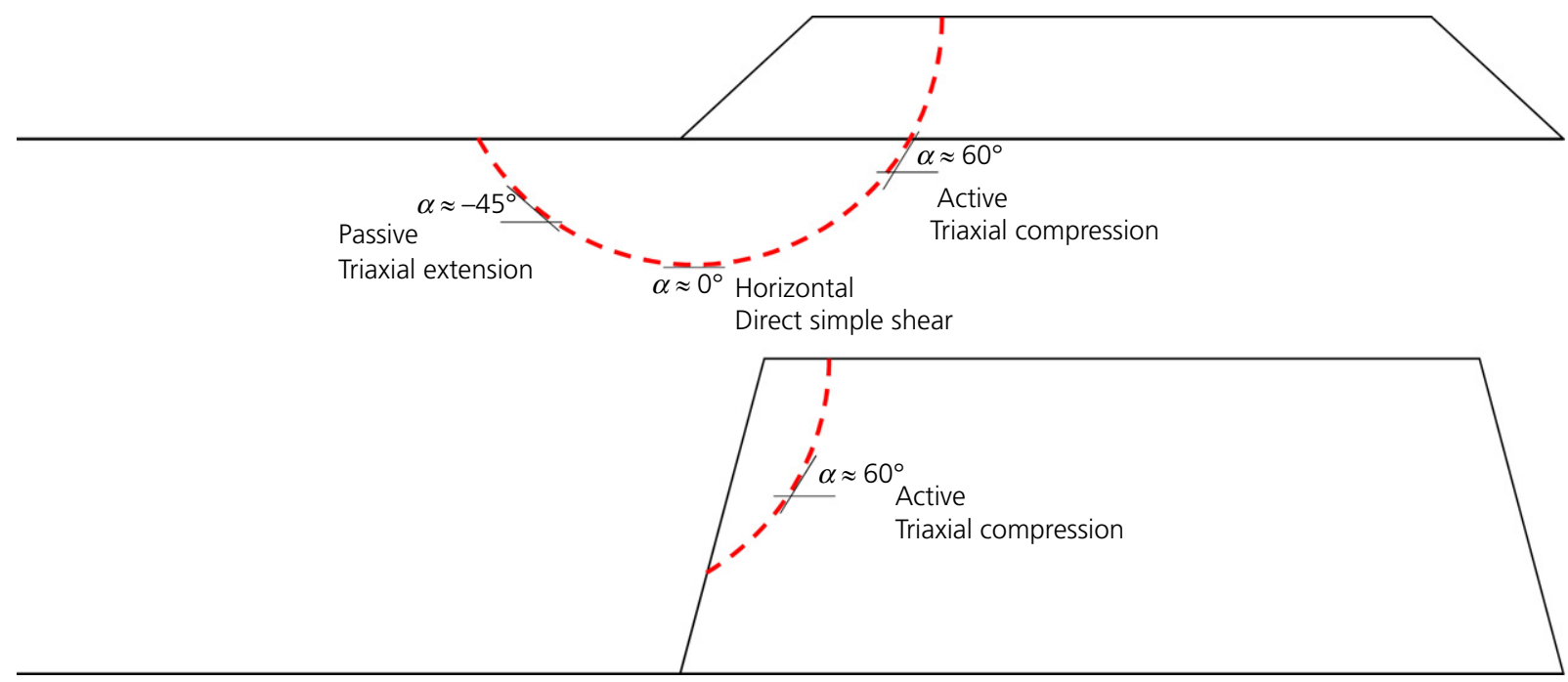

Figure 13. Relation between triaxial extension, direct simple shear and triaxial compression and orientation of failure surface for different shapes of embankments 
The correlation between the PI and the anisotropic behaviour of plastic soils has been investigated by Bjerrum (1973), Ladd et al. (1977), Mayne (1983) and Jamiolkowski et al. (1985). In Figure 14 the undrained shear strength ratio $\left(S=s_{\mathrm{u}} / \sigma^{\prime}\right)$ is compared with the PI for triaxial compression, direct simple shear and triaxial extension tests. The correlation between undrained shear ratio and PI for vane shear tests by Skempton (1957) and Bjerrum (Terzaghi et al., 1996) is also added in Figure 11. Mayne and Mitchell (1988) conducted extensive research on the relation between $S$ and PI for normally consolidated soils, which confirmed the relation as proposed by Skempton (1957). It should be noted that the individual results, upon which the linear regressions in Figure 14 are based, exhibit a certain scatter. Owing to the lack of data on the shear ratio for the industrial sludge, it is assumed that the behaviour of the sludge is similar to clay, as presented in Figure 14.

Chandler (1988) proposed conversion factors for the conversion of field vane shear test results to triaxial compression results. The authors of this paper propose the use of the conversion factors in Figure 15 for the conversion of vane shear test results, based on the anisotropic shear ratio given in Figure 14. Appropriate conversion factors are used depending on the PI and the desired anisotropic state (passive, active, direct simple shear). They represent the undrained shear strength ratio of the relevant anisotropic state to the undrained

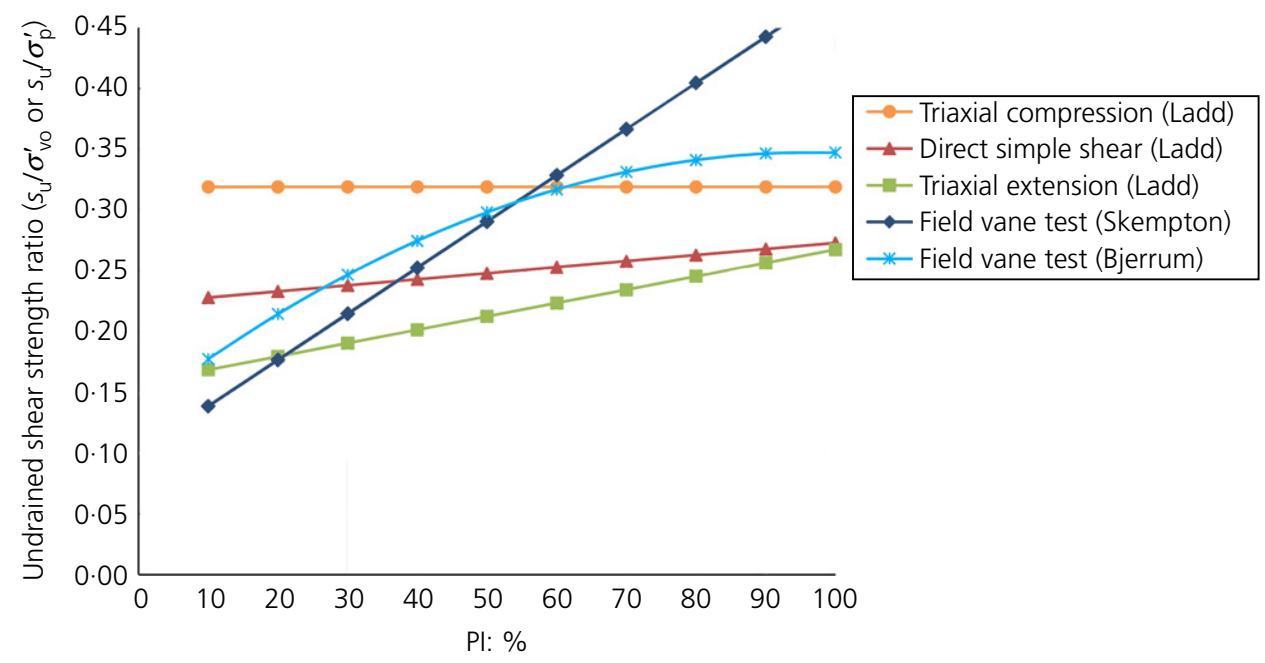

Figure 14. Influence of anisotropy on undrained shear strength of CKOU tests on normally consolidated clay and loam (Ladd, 1991) (triaxial compression, direct simple shear and triaxial extension), supplemented with suggestion for the relation between $s_{\mathrm{u}} / \sigma_{\mathrm{p}}^{\prime}$ and $\mathrm{PI}$, based on the data from field vane test by Bjerrum (Terzaghi et al., 1996) and data from field vane test by Skempton (1957)

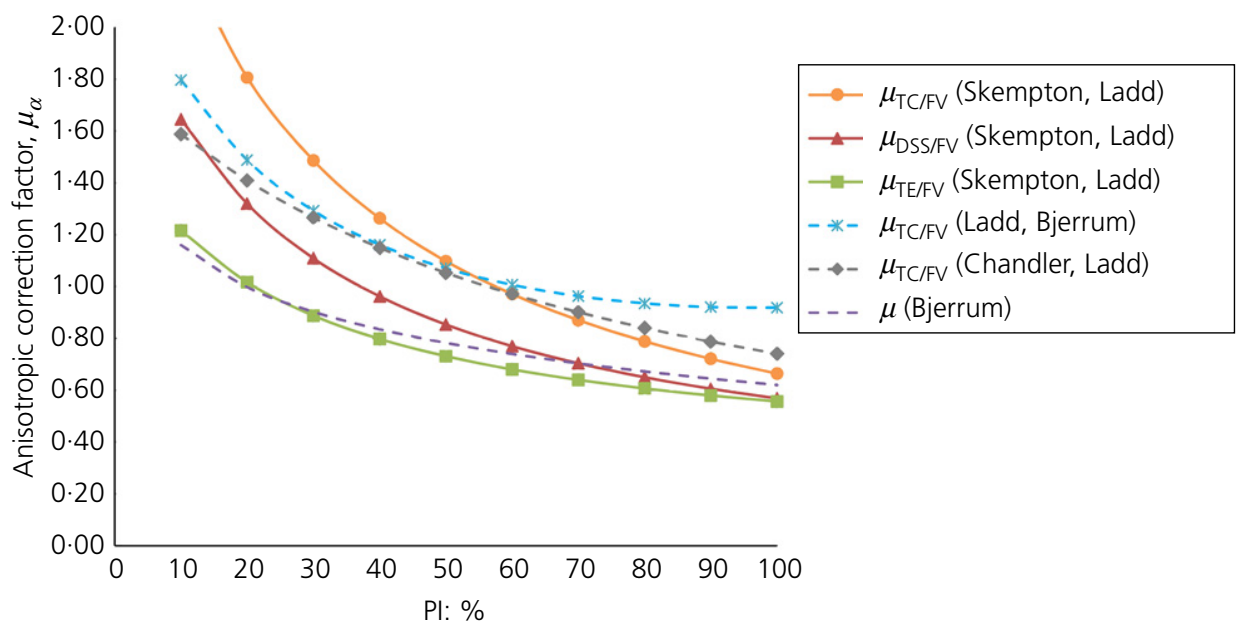

Figure 15. Anisotropic conversion factors for conversion of shear strength ratio of undrained shear resistance from field vane tests to triaxial compression, direct simple shear and triaxial extension 
vane shear strength ratio. An example for the anisotropic conversion factor $\mu_{\alpha}$ is given in Equation 2.

2. $\mu_{\alpha}=\frac{S_{\alpha}}{S_{\alpha}}: \mu_{\mathrm{TC} / \mathrm{FV}}=\frac{S_{\mathrm{TC}}}{S_{\mathrm{FV}}}=\frac{S_{\mathrm{u}, \mathrm{TC}} / \sigma_{v 0}^{\prime}}{S_{\mathrm{u}, \mathrm{FV}} / \sigma_{v 0}^{\prime}}$

where $\mu_{\mathrm{TC} / \mathrm{FV}}$ is the anisotropic factor for conversion of field vane to triaxial compression test; $S_{\mathrm{TC}}$ is the undrained shear strength ratio from the triaxial compression test (Ladd et al., 1977); $S_{\mathrm{FV}}$ is the undrained shear strength ratio from field vane test (Skempton, 1957); $s_{\mathrm{u}, \mathrm{TC}}$ is the undrained shear strength from triaxial compression test; $s_{\mathrm{u}, \mathrm{FV}}$ is the undrained shear strength from field vane test; and $\sigma_{\mathrm{v} 0}^{\prime}$ is the in situ vertical effective stress.

The proposed (anisotropic) conversion factors are presented in Figure 15 by full lines. These conversion factors are to be used on the raw vane shear test results. The vane test correction factor such as suggested by Bjerrum (1973) (Figure 15, dashed lines) is also used in one of the back-analyses of the slope failure test, to be compared with the conversion factors in the suitable material models. It is assumed that, by converting the raw vane shear test data to triaxial compression, direct simple shear or triaxial extension results, any errors are adjusted by using the conversion factor which depends on the PI.

\subsection{Strain rate effect}

The rate at which failure occurs has an influence on the shear resistance of a material. Due to the viscosity of plastic soils, a higher shear resistance is encountered when the speed of loading is increased. Chandler (1988) investigated the magnitude of the strain rate effect in vane shear tests. For clayey and loamy soils with a PI greater than 5\%, the following Equation 3 is suggested

\section{3. $s_{\mathrm{u}, t_{\mathrm{f}}} \mu_{\mathrm{R}}=s_{\mathrm{u}, t_{0}}$}

$$
\mu_{\mathrm{R}}=1.05-b(\mathrm{PI})^{0.5}
$$

$$
b=0 \cdot 015+0 \cdot 0075 \log t_{\mathrm{f}}
$$

In the above equation, $\mu_{\mathrm{R}}$ is the strain rate effect correction factor; $b$ is the time parameter; $t_{\mathrm{f}}$ is the time to failure in minutes; and $s_{\mathrm{u}, t_{0}}$ and $s_{\mathrm{u}, t_{\mathrm{f}}}$ denote the undrained shear strength corresponding to the respective time scale. With the Bjerrum correction factors for vane shear tests, the strain rate effects are taken into account by correcting the fast vane shear test according to an assumed time to failure at real slope failures. According to ASTM D2573 (ASTM, 2018) a time to failure of around $10000 \mathrm{~min}(7 \mathrm{~d})$ is generally to be used for a long-term failure. If the time to failure is assumed to be 10 $000 \mathrm{~min}$, the correction factor would be $\mu_{\mathrm{R}, 10 \quad 000^{\prime}}=0.788$ $(\mathrm{PI}=34 \%)$. In the real scale slope failure test a higher strain rate is imposed by the applied load increment. The real scale slope failure test took $6 \mathrm{~h}$, from the first loading step until failure. The corresponding correction factor is $\mu_{\mathrm{R}, 3600^{\prime}}=0.851$ $(\mathrm{PI}=34 \%)$. Besides the Bjerrum correction factor, an additional correction is therefore required in this case, to adjust the Bjerrum correction factor (which assumes long-term failure). The additional correction will be $0 \cdot 851 / 0 \cdot 788=1 \cdot 080\left(\mu_{\mathrm{R}^{\prime}}\right)$.

In the conversion of test results for undrained shear resistance measured by vane shear tests to triaxial compression, direct shear or triaxial extension tests according to Figure 15, an additional correction, taking into account the strain rate effects, is not required. The time until failure in triaxial compression/extension tests and direct simple shear test, as well as the full-scale slope failure test, is in the same order of magnitude of several hours.

\subsection{Material models}

A 2D finite-element model (Plaxis) was used to carry out a back-calculation of the slope failure test. Taking into consideration the large variation in undrained shear strength of the sludge, a similar variation in (initial) pore water pressure is expected. Hence, using the effective strength parameters in undrained loading conditions after consolidation may lead to an erroneous effective stress path and accordingly erroneous undrained shear strength. Therefore, a direct input of the undrained shear strength in a total stress analysis is preferred. As presented in Table 2, two different material models were applied for the sludge elevation. First, a Mohr-Coulomb (MC) undrained model was applied, where the results of the vane shear test were used, corrected with the correction factors by Bjerrum (1973) and an additional strain rate correction factor.

4.

$$
\begin{aligned}
\mathrm{MC}: s_{\mathrm{u}} & =\mu_{\mathrm{B} j} \mu_{\mathrm{R}} s_{\mathrm{u}, \mathrm{FV}}=0.875 \times 1.080 \times 9.73 \mathrm{kPa} \\
& =9.19 \mathrm{kPa}
\end{aligned}
$$

To take into account the anisotropic behaviour, a second simulation was carried out using the Norwegian Geotechnical Institute-active, direct simple shear, passive (NGI-ADP) material model. The NGI-ADP model (Andresen and Jostad, 1999) is an advanced undrained shear strength model. The shear strength in the material model is defined in three stress states: active (A), direct simple shear (D) and passive (P). The active undrained shear strength was determined with an anisotropic conversion factor $\left(\mu_{\alpha}\right)$ applied on the shear strength for the field vane test.

5.

$$
\begin{aligned}
\mathrm{NGI}-\mathrm{ADP}: s_{\mathrm{u}}^{\mathrm{A}} & =\mu_{\alpha} s_{\mathrm{u}, \mathrm{FV}}=1.386 \times 9.73 \mathrm{kPa} \\
& =13.48 \mathrm{kPa}, \text { with } \alpha: \mathrm{TC} / \mathrm{FV}
\end{aligned}
$$


In the finite-element model Plaxis a ratio of triaxial compression shear strength over active shear strength $\left(s_{\mathrm{u}}^{\mathrm{C}, \mathrm{TX}} / s_{\mathrm{u}}^{\mathrm{A}}\right)$ equal to 0.99 is suggested. The ratios of passive and direct simple shear strength over active shear strength $\left(s_{\mathrm{u}}^{\mathrm{P}} / s_{\mathrm{u}}^{\mathrm{A}}\right.$ and $\left.s_{\mathrm{u}}^{\mathrm{DSS}} / s_{\mathrm{u}}^{\mathrm{A}}\right)$ are derived from the graph in Figure 14 at a PI of $33.9 \%$. The relative proportions are used to define the ratios where $s_{\mathrm{u}}^{\mathrm{P}}=s_{\mathrm{u}, \mathrm{TE}}$ and $s_{\mathrm{u}}^{\mathrm{A}}=s_{\mathrm{u}, \mathrm{TC}}$.

The shear stresses at the failure load of the full-scale slope failure test $\left(33 \mathrm{kN} / \mathrm{m}^{2}\right)$ for the MC and NGI-ADP material model are presented in Figure 16. Furthermore, the incremental deviatoric shear strains illustrate the position of the theoretical shear plane.

The results of the shear stress distribution in the soil indicate the difference between the MC model and the NGI-ADP model. In the analysis using the MC material model, the shear stress is nearly constant along the critical slip surface. No relation between the magnitude of the shear stress and the position on the slip surface is observed. The shear stress distribution in the NGI-ADP model fluctuates along the slip surface and reaches the highest stress level in the active zone

Table 2. Model input data for sand and sludge elevation (MC and NGI-ADP)

\begin{tabular}{|c|c|c|c|c|c|}
\hline Parameter & Symbol & Sand & $\begin{array}{l}\text { Sludge } \\
\text { elevation }\end{array}$ & $\begin{array}{l}\text { Sludge } \\
\text { elevation }\end{array}$ & Unit \\
\hline Material model & Model & MC & NGI-ADP & $M C$ & - \\
\hline Behaviour & Type & Drained & Undrained & Undrained & - \\
\hline Unsaturated unit weight & Yunsat & 17 & 16 & 16 & $\mathrm{kN} / \mathrm{m}^{3}$ \\
\hline Saturated unit weight & $\gamma_{\text {sat }}$ & 20 & 16 & 16 & $\mathrm{kN} / \mathrm{m}^{3}$ \\
\hline Young's modulus & $E$ & 20000 & - & 3600 & $\mathrm{kN} / \mathrm{m}^{2}$ \\
\hline Poisson ratio & $v$ & $0 \cdot 3$ & 0.495 & 0.495 & - \\
\hline Cohesion & $c^{\prime}$ & 0.5 & - & - & $\mathrm{kPa}$ \\
\hline Friction angle & $\phi^{\prime}$ & 35 & - & - & degrees \\
\hline Undrained shear strength & $s_{u}$ & - & - & $9 \cdot 2$ & $\mathrm{kPa}$ \\
\hline Void ratio & $e$ & 0.5 & $2 \cdot 0$ & $2 \cdot 0$ & - \\
\hline Ratio unloading/reloading shear modulus over active shear strength & $G_{u r} / s_{u}^{A}$ & - & 250 & - & - \\
\hline Reference active shear strength & $S_{u}^{A_{\text {ref }}}$ & - & $13 \cdot 5$ & - & $\mathrm{kPa}$ \\
\hline Ratio of triaxial compression shear strength over active shear strength & $s_{u}^{C, T X} / s_{u}^{A}$ & - & 0.99 & - & - \\
\hline Ratio of passive shear strength over active shear strength & $s_{u}^{P} / s_{u}^{A}$ & - & 0.610 & - & - \\
\hline Ratio of direct simple shear strength over active shear strength & $s_{u}^{D S S} / s_{u}^{A}$ & - & 0.752 & - & - \\
\hline
\end{tabular}

MC

Shear stress

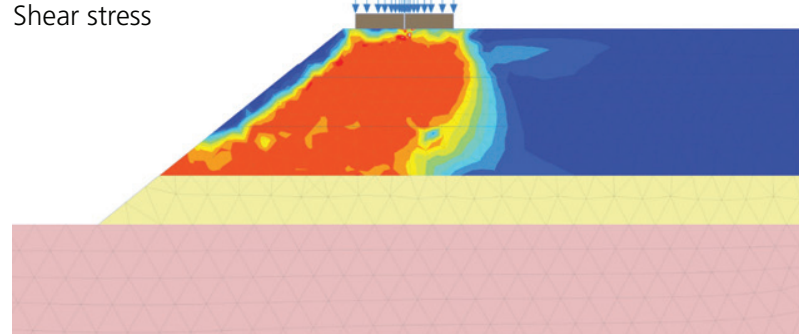

NGI-ADP

Shear stress

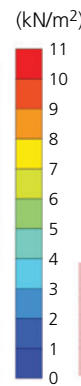

$\left(\mathrm{kN} / \mathrm{m}^{2}\right) \quad \mathrm{NGI}-\mathrm{ADP}$

Shear strain

Shear strain

Shear strain
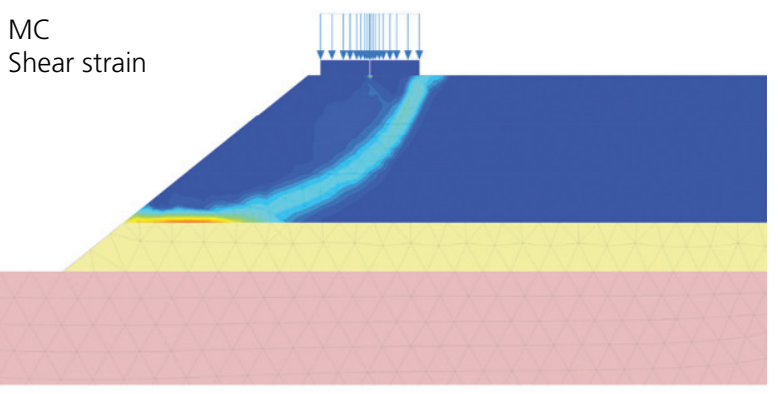

Sher strain
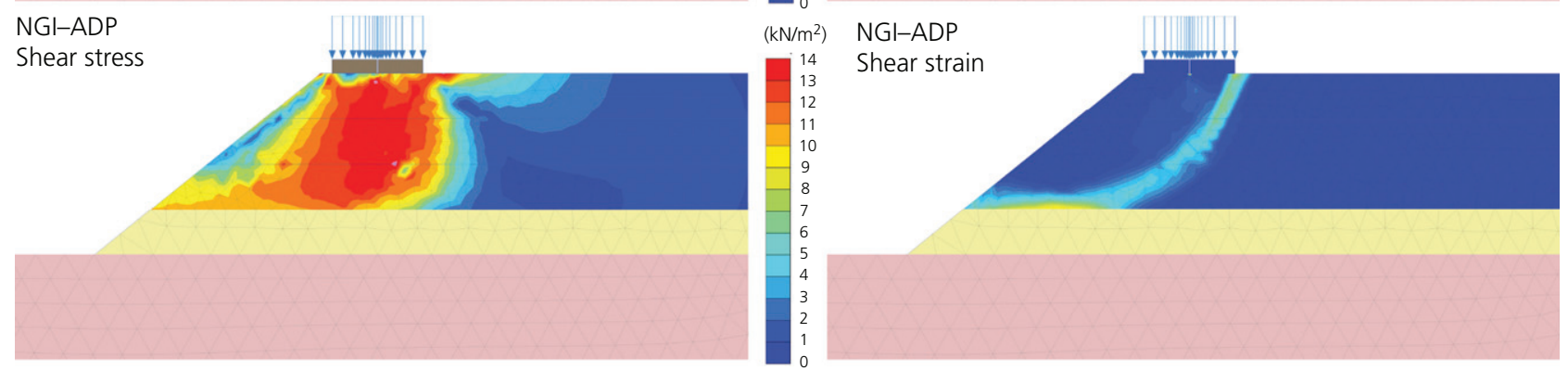

Figure 16. Shear stress and shear strain in elevation in the MC and NGI-ADP model at a crest load of $33 \mathrm{kN} / \mathrm{m}^{2}$. The location of the maximum shear strain indicates the position of the shear plane 


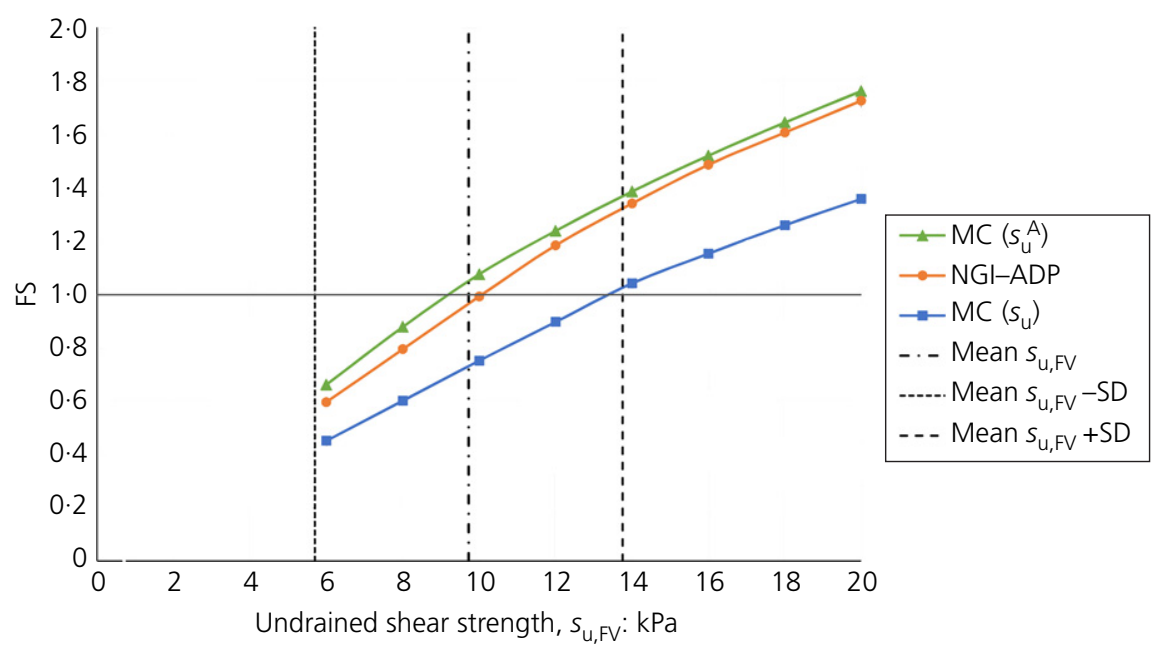

Figure 17. Calculated FS (3D) of the sludge embankment with a load of $33 \mathrm{kN} / \mathrm{m}^{2}$ for a range of undrained (field vane) shear strength with $\mathrm{MC}$ and NGI-ADP material models

$\left(30^{\circ}<\alpha<60^{\circ}\right)$. The horizontal section, near the sand layer, is smaller in the MC model compared to the NGI-ADP model, visualised by the incremental deviatoric strain in Figure 16. Subsequently the active section (below the crest load) in the NGI-ADP model is steeper, whereas in the MC model the curve is less steep and smooths out in a circular form. The model results are in keeping with the expectation that the choice of material model not only influences the shear stresses but can also change the position of the slip surface.

A comparison of the actual position of the shear surface with those assumed in the analyses was not possible based on the measured deformations. Based on the observation during the test, it can be assumed that the shear surface starts below the bulge at the front of the embankment and ends at the crack at the crest behind the crane mats.

\subsection{Results of back-calculation}

Figure 17 presents the results of the back-calculation of the undrained shear strength of the industrial sludge embankment with a crest load of $33 \mathrm{kN} / \mathrm{m}^{2}$. The FS is plotted against the (raw) vane shear strength. However, in the analysis the corrected and converted shear strengths are applied. The average vane shear strength from the field tests is indicated, as well as the average value plus and minus the SD. The FS from the 2D finite-element analysis is converted to the corresponding $3 \mathrm{D}$ FS. In the MC model first of all the average shear strength $\left(s_{\mathrm{u}}\right)$ was implemented to calculate the corresponding FS. Second, the active undrained shear strength $\left(s_{\mathrm{u}}^{\mathrm{A}}\right)$, as determined for the NGI-ADP model, was used in the MC model to compare these results with the NGI-ADP model. The decrease of the FS (assuming the average $s_{\mathrm{u}}$ ) with the increase of the crest load is presented in Figure 18.
The MC model, with the use of the correction factors by Bjerrum for the undrained shear strength from vane shear tests, underestimates the stability of the sludge elevation. A FS of only 0.73 was reached for the average undrained field vane shear strength in the MC model. This indicates that the test embankment should have collapsed at a lower crest load or, alternatively, that the shear resistance of the sludge is higher than assumed in the analysis.

When the active undrained shear strength $\left(s_{\mathrm{u}}^{\mathrm{A}}\right)$ is used in the MC model, the FS achieved increases to $1 \cdot 05$, thus approximating the actual failure of the test embankment. In the MC $\left(s_{\mathrm{u}}^{\mathrm{A}}\right)$ simulation, it is assumed that all the soil shears in active shear, resulting in a higher shear resistance. This assumption is, however, an overestimation given the critical slip surface illustrated in Figure 16, where a horizontal shear section occurs.

In the NGI-ADP material model the various anisotropic stress states are taken into account at the exact location. A FS of 0.96 is computed with the NGI-ADP model, hence corresponding well with the actual slope failure when using the average undrained field vane shear strength.

Both the NGI-ADP model and the MC $\left(s_{\mathrm{u}}^{\mathrm{A}}\right)$ model give a reasonable representation of the FS for the test set-up at failure, if the average shear strength is assumed. Nevertheless, it should be noted that the variability of the undrained vane shear strength, determined with the field vane, is significant. Furthermore, the FS is highly sensitive to the undrained shear strength. The FS for NGI-ADP and MC $\left(s_{\mathrm{u}}^{\mathrm{A}}\right)$ ranges from approximately 0.6 to 1.4 over one $\mathrm{SD}(+$ and - ) from the mean value. The large scatter of the vane shear test results is not a direct consequence of the chosen test method, but is mainly due to the variation of the material itself. The process 


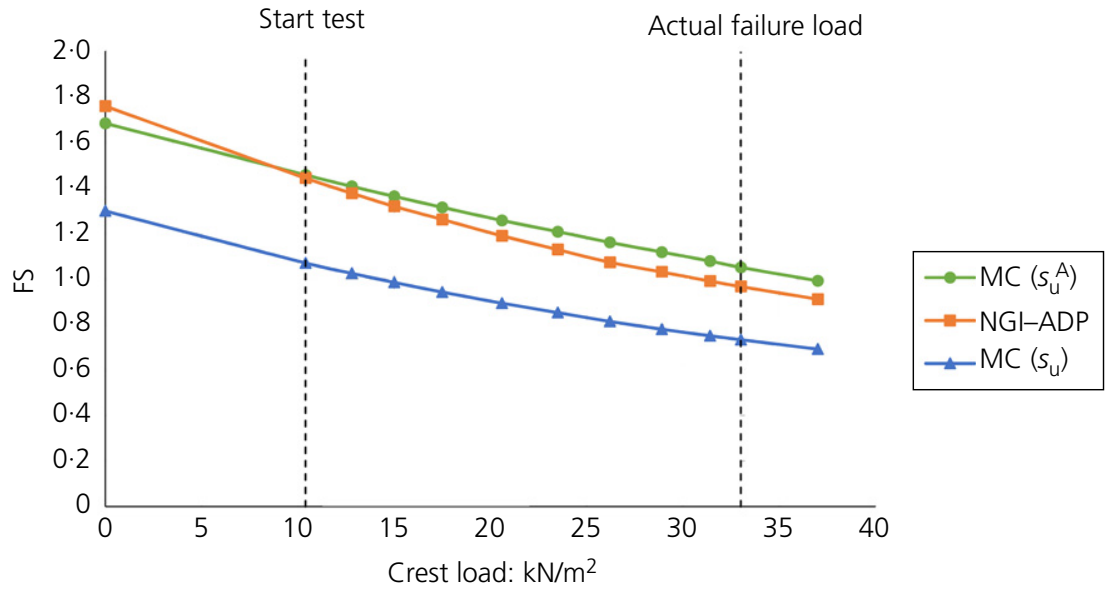

Figure 18. Calculated FS (3D) of the sludge embankment during the different steps of the slope failure test with MC and NGI-ADP material models

of natural consolidation determines the undrained shear strength. By building the embankment with various layers of excavated sludge which have been consolidated at different stress levels, the embankment is a mixture of highly and lightly consolidated sludge. Given the relatively small scale of the (forced) slope failure test, it can be assumed that the slip surface will run through both strong and weak layers. Therefore, the average shear strength is used in the back-analysis. When performing stability checks on larger slopes, an appropriate method for taking into account the spread of the shear strength must be used to determine the characteristic values. Because of the large spread of the results, applying a normal distribution will, however, lead to a very low characteristic value. The choice of the most appropriate method (normal, log-normal and so on) to quantify the distribution is not considered in this paper.

A sensitivity analysis is performed to verify the influence of the variation of the PI $(33.9 \% \pm 3.0 \%)$ on the FS. In the MC analysis a variation of the PI of $\pm 3.0 \%$ resulted in a nearly equal variation of $\pm 2.7 \%$ of the FS (range: $1 \cdot 0<\mathrm{FS}<1.5$ ). With the MC $\left(s_{\mathrm{u}}^{\mathrm{A}}\right)$ and NGI-ADP analysis, the variation of the FS lies between $+3 \cdot 7 \%$ and $-4 \cdot 1 \%$. The (small) unequal distribution is due to the curve of the correction factors given in Figure 15. As expected, a decrease in PI will have a larger impact on the correction factor $\left(\mu_{\alpha}\right)$ than a similar increase.

\subsection{Slope failure test after consolidation}

The full-scale slope failure test consisted of two phases. The first phase was executed on one half of the test embankment, shortly after construction, as described above. In the second phase, the slope failure test was to be repeated 1 year later on the remaining part of the embankment (test area B, Figure 6). The objective was to evaluate the influence of consolidation of the industrial sludge. After determining the vane shear resistance, at locations spread over the entire embankment in the context of the first testing phase, repeated measurements were conducted in zone B several months later. The results are given in Figure 19.

Over a period of 5 months (winter and spring), the average undrained shear strength had roughly doubled from $16 \cdot 2 \mathrm{kPa}$ to $35.4 \mathrm{kPa}(\mathrm{SD}=15.5 \mathrm{kPa} ; \mathrm{COV}=0.44)$. Ten months after the first vane shear test, the shear resistance had increased further up to around $250 \%$ of the initially measured values $\left(s_{\mathrm{u}, \text { ave }}=40.9 \mathrm{kPa} ; \mathrm{SD}=18.2 \mathrm{kPa} ; \mathrm{COV}=0.44\right)$. Because of the strong increase of the undrained shear strength, the initial test set-up at test area A could not be repeated because of the high loads required to trigger slope failure. The results of the vane shear tests indicate a significant increase in undrained shear strength. The consolidation of the sludge, however, cannot result in a shear strength of around $40 \mathrm{kPa}$ if the internal stress can only be generated by its own weight. At the maximum depth the maximum effective stresses are too limited $\left(\sigma_{\max }=3 \mathrm{~m} \times 16 \mathrm{kN} / \mathrm{m}^{3}=48 \mathrm{kN} / \mathrm{m}^{2}\right)$. The additional increase in shear strength will most likely be due to suction stresses, caused by dehydration of the sludge during the resting period. With the presence of the sandy drainage layer below the sludge layers, the phreatic surface is kept below this layer, resulting in an additional artificial effective stress (suction) in the sludge.

The suction stresses are, however, most often only temporary and caution should be maintained when counting on them. Variations in phreatic level or precipitation may lead to a rapid decline of the artificial additional effective stresses caused by suction. Nevertheless, these additional effective stresses will have led to an overconsolidation of the sludge which will have a positive influence on the sludge behaviour during further elevation. 


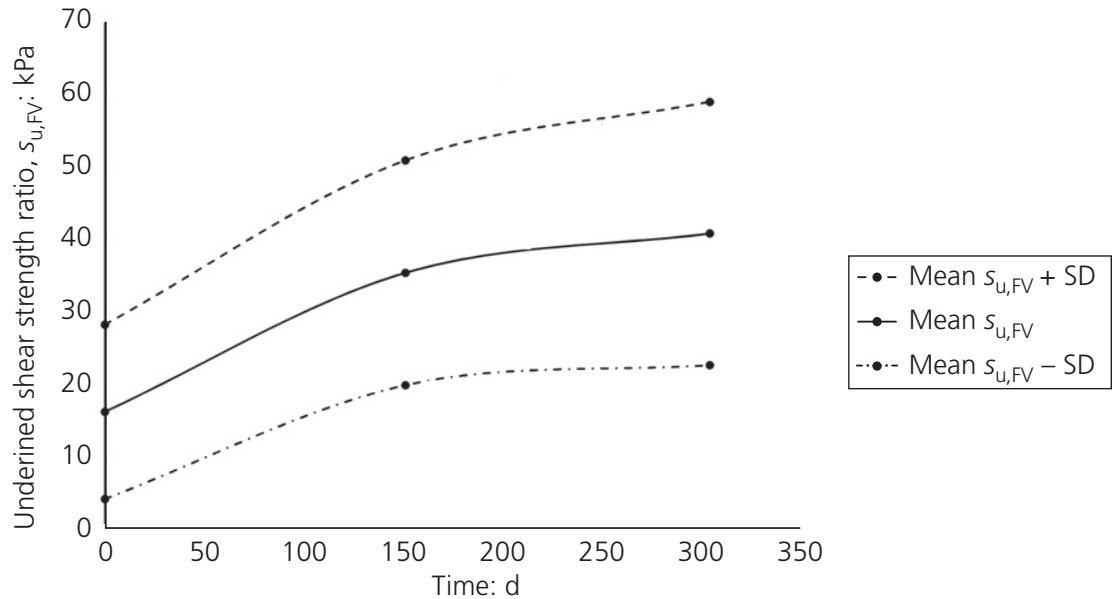

Figure 19. Average and SD of undrained shear strength from vane shear test at location B over a period of 10 months

\section{Conclusions}

A full-scale slope failure test was conducted on an embankment constructed with industrial calcium fluoride sludge to determine the actual shear strength at failure. In situ vane shear tests were used to estimate the undrained shear strength of the sludge.

The in situ vane shear test results exhibited a large spread, which is probably the consequence of the origin of the material (varying sludge-sand mixture), the initial (pre)consolidation and the various manipulations (excavation, dumping, spreading and so on) to which the material is subjected. The main advantage of the vane shear test is the simplicity of the test, which makes it possible to obtain a large number of measurements. A reliable variation of the undrained shear strength can thus be determined. In combination with laboratory tests (triaxial tests, direct simple shear and so on) the accuracy of the vane shear test might be increased. However, a direct correlation between laboratory tests on soil samples and in situ tests near the sampling location is hard to establish in this heterogeneous material.

To correct the undrained shear strength, measured in situ with the vane shear apparatus, to the actual shear strength in slope failure, the Bjerrum correction factor was used as well as an alternative method. The Bjerrum correction factor applies, among others, a correction for the anisotropy in which the vane shear test is assumed to be equivalent to the average anisotropy of triaxial extension (passive), direct simple shear and triaxial compression (active) tests. In the presented case, this can be a conservative assumption. The alternative method consists of converting the vane shear strength to a more suitable anisotropic shear strength - that is, passive (triaxial extension), direct simple shear or active (triaxial compression) shear strength. The current assumed conversion factors are solely based on literature findings. To reduce the uncertainty of these factors, it will be necessary to perform and compare several direct shear tests, triaxial tests and vane shear tests on the material concerned.

A back-calculation of the slope failure test was made to compare the measured in situ shear strength with the theoretical shear stresses arising in a 2D model of the slope at failure. Two different approaches, MC and NGI-ADP, were used to determine the shear strength of the sludge in the finite-element model (Plaxis) based on the average vane shear tests and to calculate the FS at the critical failure load of the slope failure test. The analysis of the full-scale slope failure test based on the average corrected (Bjerrum) undrained shear strength from the vane shear test, using the MC material model, resulted in an underestimation of the actual shear strength. The anisotropic converted shear strength values were used in the NGIADP material model. Also a second MC model was used which included the $s_{\mathrm{u}}^{\mathrm{A}}$ value (active undrained shear strength) instead of the corrected shear strength value. Both methods using the anisotropic values approached the results of the slope failure test. The position the shear plane could not, however, be verified and checked with the theoretical shear plane. For larger slopes it is advised to use the NGI-ADP model, as the different anisotropic shear strength ratios (active, direct simple shear and passive) are implemented in the model, whereas in this example the assumed main failure mechanism (active shear) was manually assigned in the adapted MC model.

It should be noted that the back-calculations are based on the average values of the vane shear tests. The material variability was not accounted for. The sensitivity analysis indicates that the FS is highly sensitive for variations of the undrained shear strength. It was assumed that, owing to the rather small failure zone of the slope failure test, the average shear strength is representative for the shear resistance. Nevertheless, the significant spread leads to a high degree of uncertainty. For stability 
analysis of larger elevations, the spread of the material characteristics must be taken into account through an appropriate probabilistic design.

\section{Acknowledgement}

The authors would like to thank Tessenderlo Group for the long-lasting collaboration and support in this project.

\section{REFERENCES}

Andresen L and Jostad HP (1999) Application of an hardening model for undrained response of saturated clay. Proceedings of NUMOG VII, Graz, Austria (Pande GN, Pietruszczak S and Schweiger HF (eds)). CRC Press, Boca Raton, FL, USA, pp. 581-585.

ASTM (2018) D2573/D2573M-18: Standard test method for field vane shear test in saturated fine-grained soils. ASTM International, West Conshohocken, PA, USA.

ASTM (2017) D4318-17e1: Standard test methods for liquid limit, plastic limit, and plasticity index of soils. ASTM International, West Conshohocken, PA, USA.

Azzouz AS, Baligh MM and Ladd CC (1983) Corrected field vane strength for embankment design. ASCE Journal of Geotechnical Engineering 109(5): 730-734.

Bjerrum L (1973) Problems of soil mechanics and construction on soft clays. Proceedings of the 8th International Conference on Soil Mechanics and Foundation Engineering, Moscow, Russia (Tsytovich NA and Chetyrkin NS (eds)). Kluwer Academic Publishers-Plenum Publishers, Moscow, Russia, vol. 3, pp. 11-159.

Chandler RJ (1988) The In Situ Measurement of the Undrained Shear Strength of Clays Using the Field Vane. Vane Shear Strength Testing in Soils: Field and Laboratory Studies. American Society for Testing and Materials, West Conshohocken, PA, USA, ASTM STP 1014, pp. 13-44.

Jamiolkowski M, Ladd CC, Germaine JT and Lancellotta R (1985) New developments in field and laboratory testing of soils. Proceedings of the 11th International Conference on Soil Mechanics and Foundation Engineering, San Francisco, CA, USA, Publications Committee of XI ICSMFF, Balkema, Rotterdam, The Netherlands, San Francisco, CA, USA, vol. 1, pp. 57-154.
Ladd CC (1991) Stability evaluation during staged construction. 22nd Karl Terzaghi lecture. Journal of Geotechnical Engineering 117(4): 540-615.

Ladd CC, Foott R, Ishihara K, Schlosser F and Poulos HG (1977) Stress deformation and strength characteristics. Proceedings of the 9th International Conference on Soil Mechanics and Foundation Engineering, Tokyo, Japan, Kluwer Academic Publishers-Plenum Publishers, Tokyo, Japan, vol. 2, pp. 421-494.

Mayne PW (1983) Discussion: undrained shear strength anisotropy of normally consolidated cohesive soils. Soils and Foundations 23(4): 143-146.

Mayne PW and Mitchell JK (1988) Profiling of OCR in clays by field vane. Canadian Geotechnical Journal 25(1): 150-157.

Skempton AW (1957) Discussion. Proceedings of the Institution of Civil Engineers 7(2): 305-307.

Tennekoon J (2007) Geotechnical characterization of an industrial sludge and numerical analysis of sludge dam behavior. $\mathrm{PhD}$ thesis, Department of Civil Engineering, KU Leuven, Leuven, Belgium.

Terzaghi K, Peck RB and Mesri G (1996) Soil Mechanics in Engineering Practice, 3rd edn. John Wiley \& Sons, New York, NY, USA.

Verreydt K, Van Gemert D, Houtmeyers J and Van Waelderen J (2014) Redevelopment of old sludge reservoirs. Proceedings of 7th International Congress on Environmental Geotechnics ICEG 2014, Melbourne, Australia (Bouazza A, Brown B and Yuen S (eds)) Curran Associates, Inc, Red Hook, NY USA, pp. 644-649.

Yonatan PH, Maertens J, Van Gemert D, Houtmeyers J and Goorden M (2008) Management and re-use of contaminated industrial sludge from geotechnical point of view. Proceedings of the 1st International Conference on Hazardous Waste Management, Chania, Crete, Greece. Technical University of Crete, Chania, Greece, pp. 263-264.

Yonatan PH, Maertens J, Van Gemert D, Houtmeyers J and Goorden M (2009a) Industrieel slib voor bouwen van een dijk: geotechnisch gedrag en numerieke simulatie. Tijdschrift Geotechniek 13(2): 46-54 (in Dutch).

Yonatan PH, Tennekoon J, Maertens J et al. (2009b) Construction of an embankment on and with an improved soft industrial sludge. In Proceedings of the 2nd International Workshop on Geotechnics of Soft Soil-Focus on Ground Improvement, Glasgow, UK (Karstunen M and Leoni M (eds)). CRC Press, Boca Raton, FL, USA, pp. 434441. 